\title{
Anogenital warts in children: sexual abuse or unintentional contamination?
}

\author{
Verrugas anogenitais na infância: \\ abuso sexual ou contaminação não-intencional?
}

Lisieux Eyer de Jesus 1,2

Oscar Luís Lima e Cirne Neto 1,2

Leila Maria Montei ro do Nascimento 2

Rejane Costa Araújo 2

Andréa Agostinho Baptista 2

1 Hospital Universitário Antônio Pedro, Universidade Federal Fluminense.

Rua Marquês de Paraná s/n, Niterói, RJ

24033-900, Brasil.

2 Hospital Municipal Jesus. Rua Oito de Dezembro 717, Rio de Janeiro, RJ 20550-200, Brazil.
Abstract Anogenital warts (AGW) were recently recognized in children, and their significance as an index of childhood sexual abuse is controversial. We report our transdisciplinary approach (including a pediatric surgeon, psychol ogist, social worker, ethics expert, and occasionally law enforcement agents) and its results in a group of 17 children with AGW treated at the public pediatric referral hospital in Rio de Janeiro, Brazil, during a 3-year period (1996-1999). All children were treated by electrocauterization of the warts, tested for other STDs, and submitted to perineal examination under anesthesia. Families recei ved psycho-social counsel ing as necessary and cases were referred to child protection and law enforcement agents when indicated according to Brazilian legislation. We identified a high incidence of sexual abuse ( 8 children, $5 / 7>5$ years old), with 3 patients inconclusive as to sexual abuse and 7 cases of perinatal transmission $(5 / 8<4$ years old). We conclude that AGW are indeed a strong sign of suspicion for sexual abuse in children, especially but not exclusi vely $>5$ years of age. However, strong support and a transdisciplinary approach to the children and their families is necessary to identify it.

Key words Child Abuse, Sexual; Condyl omata Acuminata; Human Papillomavirus; Sexually Transmitted Diseases

Resumo Verrugas anogenitais (VAG) são de reconhecimento recente na criança e seu significado como sinal de abuso sexual é controverso. Relatamos nossa abordagem multidisciplinar (cirurgi ão pediatra, psi cólogo, assistente social, consel hei ro de ética e eventual mente agente legal ) e seus resultados, num grupo de 17 crianças com VAG tratadas em um hospital público de referência no Rio de Janeiro, Brasil, em um período de três anos (1996-1999). Todos foram tratados por el etrocoagulação das verrugas, testadas para outras DSTs, e submeti dos a um exame perineal sob anestesia. Todas as famílias foram amparadas pel os assi stentes sociais e psi cól ogos na medida do necessário, e casos de violên cia comprovada ou suspeita foram encaminhados de acordo com as leis brasi lei ras. Foi descoberta uma alta incidência de abuso sexual previamente insuspeito (oito crianças, 5/7 dos maiores de cinco anos de idade), três casos foram inconclusivos quanto à presença de abuso sexual e sete foram considerados transmissão não agressi va (5/8 dos menores de quatro anos de idade). Concl uímos queVAG em crianças são mui to sugesti vas de abuso sexual, em especial, mas não exclusivamente, em idade escol ar, mas é necessário amplo suportee abordagem multidisci plinar para evidenciar o abuso ocorrido.

Palavras-chave Maus-Tratos Sexuais Infantis; Condiloma Acuminado; Papilomavírus Humano; Doenças Sexualmente Transmissíveis 


\section{Introduction}

The presence of anogenital warts (AGW) in children is a clinical situation only recently described in medical literature, and medical attitudes towards it are still a controversial issue, as their mechanisms of transmission, epidemiology and future consequences for the patients are doubtful as yet. There are relatively few articles dedicated to this issue, especially in comparison to the adult literature, although the volume of information about this theme is growing progressively.

One of the difficulties in dealing with AGW in children is the possibility of sexual abuse being the cause of the problem, and this is the main point of controversy in literature, as some authors (Cohen et al., 1990; Heaton, 1995; Obalek et al., 1990) suggest that the disease is mainly transmitted by non-intentional transmission or auto inoculation in childhood. Those authors opinions were good news and were readily and well accepted by pediatricians and dermatologists, but, unfortunately, they may represent the truth only in a selected age group, and, even so, after excluding the possibility of sexual abuse beyond reasonable doubt. As a matter of fact, the exclusion of the hypothesis of sexual abuse depends on an entire multidisciplinary analysis, on spontaneous report of the fact by the child, physical irrefutable evidence of abuse or the presence of someone to testify over the fact, which can be very difficult, uncommon, or even impossible to obtain, especially in preschoolers or babies.

We relate here the experience of a pediatric surgical service with AGW in children up to 12 years old, emphasizing that sexual aggression represents the main route of human papillomavirus (HPV) contamination in children over 5 and a possible cause for the disease in younger ones. The diagnosis of non-intentional contamination for the transmission of HPV to children remains to be confirmed after excluding sexual abuse, and we think that a multidisciplinary and careful assessment of each patient is necessary.

\section{Patients and methods}

We relate here a 3-year (Dec 1996-Jul 1999) experience of a pediatric referral surgical service in the treatment of 17 patients. The cases related do not represent all cases referred to at our hospital, but the cases referred by our dermatologists to one of the authors (L. E. J.). Criteria for referring AGW were no response to topical treatment or spontaneous option of the parents for surgical treatment (electrocoagulation of lesions), exclusively. There were no patients referred because of any suspicion of sexual abuse and there were no refusals to participate in the study. All the parents were informed that the possibility of sexual abuse was to be considered as a cause of AGW and that the patients would be investigated by our multidisciplinary team, and they agreed with the protocol.

All of the patients were evaluated by a multidisciplinary team consisting of a surgeon ( $L$. E. J.), a social worker (L. M. M. N.), and a psychologist. An ethics expert (O. L. L. C. N.) and law enforcement agents were consulted as necessary. All the parents received initially an explanation concerning the means of transmission of HPV to children and the importance of excluding unknown sexual abuse and co-infecting sexually transmitted diseases (STD). After informed consent, the patients were then included in a prospective study protocol. This included a careful medical, behavioral and social history collected by the team, a complete physical examination done by the surgeon under anesthesia, electrocoagulation of the lesions as treatment and exclusion of associated STDs. After these initial procedures, the children and their families were followed by the surgeon, the psychologist, and the social worker for at least 6 months.

Criteria to consider a case as sexual abuse for this study were the presence of a second sexually transmitted disease, the presence of a testimony, an irrefutable physical proof of the episode or - most commonly - the report of the episode(s) by the child, spontaneous or after a careful approach by our social worker or psychologist (Bowen \& Aldous, 1999; Paradise, 1990). Cases with serious behavioral problems detected, not explained by other means, with histories suggestive of abuse were considered as probable abuse cases.

\section{Results}

Ten patients were females and 7 males, ages ranged from 1 to 9 years for males (mean 5.1 year old - y. o.) and 1 to 8 y.o. for females (mean 3.4 y.o.). Seven patients were $<3$ y.o. (table 1 ). Extra genital warts were looked for in all children, and were found in only 2 patients (one abused, one inconclusive). There appeared another knee common wart in a patient, but only after treatment for AGW. Six of the mothers were known to be contaminated with HPV and one mother had regular unprotected sexual ac- 
General data.

\begin{tabular}{|c|c|c|c|c|c|c|}
\hline Patient & Sex & Age (years) & Cutaneous warts & Mother HPV status & AGW transmitted by & Data \\
\hline 1 & $\mathrm{~F}$ & 4 & No & Unknown & Probable abuse & $\begin{array}{l}\text { Child disappeared for } 24 \mathrm{~h} \text {, was } \\
\text { found } 2 \text { months before lesions } \\
\text { appeared, dirty and in panic, } \\
\text { incapable of relating what } \\
\text { had happened. }\end{array}$ \\
\hline 2 & $\mathrm{~F}$ & 3 & No & Unknown & Abuse & $\begin{array}{l}\text { Mother twice denounced for child } \\
\text { abuse, not cooperative, admits } \\
\text { abuse as probable and refuses to } \\
\text { denounce aggressor. Sexually } \\
\text { promiscuous, drug addict, HIV (+). }\end{array}$ \\
\hline 3 & $\mathrm{~F}$ & 2 & No & AGW & Perinatal & $\begin{array}{l}\text { AGW in the mother, no history } \\
\text { of abuse. }\end{array}$ \\
\hline 4 & M & 9 & Yes, knee & Unknown & Inconclusive & $\begin{array}{l}\text { Abuse could not be proved. } \\
\text { Unexplained perianal hematoma } \\
\text { and behavioral abnormalities. }\end{array}$ \\
\hline 5 & M & 8 & $\begin{array}{l}\text { Yes, after treating } \\
\text { AGW }\end{array}$ & Unknown & Probable abuse & $\begin{array}{l}\text { Anomalous behavior. Represents } \\
\text { persecution by older man in } \\
\text { psychotherapic sessions. }\end{array}$ \\
\hline 6 & $\mathrm{~F}$ & 3 & No & AGW & Perinatal & $\begin{array}{l}\text { AGW in the mother, no history } \\
\text { of abuse. }\end{array}$ \\
\hline 7 & $\mathrm{~F}$ & 1 & No & AGW & Perinatal & $\begin{array}{l}\text { AGW in the mother, no history } \\
\text { of abuse. }\end{array}$ \\
\hline 8 & M & 1 & No & $\begin{array}{l}\text { Negative } \\
\text { Gynecological exam }\end{array}$ & Inconclusive & $\begin{array}{l}\text { Abuse not proved. Mother and } \\
\text { father tested, not carriers. No } \\
\text { common warts in child or scars. }\end{array}$ \\
\hline 9 & M & 8 & No & Unknown & Abuse & $\begin{array}{l}\text { Abuse by homosexual neighbour, } \\
\text { denounced by child. Child paid to } \\
\text { allow abuse. Other children also } \\
\text { victims. Aggressor arrested. }\end{array}$ \\
\hline 10 & M & 6 & Yes & Unknown & Abuse & $\begin{array}{l}\text { Domestic abuse by } 16 \text { y.o. cousin. } \\
\text { Denounced by child. }\end{array}$ \\
\hline 11 & $\mathrm{~F}$ & 2 & No & $\begin{array}{l}\text { Negative after } \\
\text { Gynecological exam }\end{array}$ & Probable abuse & $\begin{array}{l}\text { Abnormal behavior, drug addicted } \\
\text { parent, no other evidence } \\
\text { of transmission. }\end{array}$ \\
\hline 12 & $\mathrm{~F}$ & 6 & No & Presumed carrier & Abuse & Domestic abuse by cousin. \\
\hline 13 & M & 2 & No & $\begin{array}{l}\text { Negative after } \\
\text { Gynecological exam }\end{array}$ & Inconclusive & $\begin{array}{l}\text { No AGW in the mother, no history } \\
\text { of abuse, no other mechanism of } \\
\text { transmission detected. }\end{array}$ \\
\hline 14 & $\mathrm{~F}$ & 5 & No & AGW & Inconclusive & $\begin{array}{l}\text { AGW in the mother (vulvar } \\
\text { condylomata), no history of abuse, } \\
\text { history of sharing towels with } \\
\text { mother. }\end{array}$ \\
\hline 15 & $\mathrm{~F}$ & 7 & No & Unknown & Abuse & $\begin{array}{l}\text { Abuse by adolescent in school, } \\
\text { disclosed by the child. Behavioral } \\
\text { abnormalities. Rejection to school. }\end{array}$ \\
\hline 16 & M & 2 & No & AGW, HIV (+) & Perinatal & $\begin{array}{l}\text { AGW in the mother, no history } \\
\text { of abuse. }\end{array}$ \\
\hline 17 & $\mathrm{~F}$ & 1 & No & AGW & Perinatal & $\begin{array}{l}\text { AGW in the mother, no history } \\
\text { of abuse. }\end{array}$ \\
\hline
\end{tabular}

AGW = anogenital warts; HPV = human papillomavirus; HIV = human immunod eficiency virus. 
tivity with a contaminated man. In 3 of the other mothers HPV infection was initially excluded by gynecologic examination and Papanicolaou tests. Seven mothers were not evaluated for HPV disease by a gynecologic examination ( 6 mothers of abused children, and the mother of a 9 y.o. male in whom we could not find the means of transmission for certainty, and that was lost to follow up). In none of these 7 mothers there was a history of sexual activity with a known contaminated partner or an abnormal previous gynecologic examination. A father had a penile condyloma acuminatum and 2 fathers were examined by an urologist to exclude condylomatous lesions. The other 9 fathers were not medically evaluated, but there were no signs of disease related by their female partners (Table 1 ). All of the mothers and fathers for whom there was no macroscopic evidence for HPV disease or a related gynecologic or urologic evaluation were counseled to see a doctor, but we could not obtain all the results of their examinations, as the ones that looked for a doctor were seen by other medical services.

Clinical presentation included multiple perineal warts in vulva, vaginal fornix and hymen (9/10 girls), perianal lesions (7/ 10 girls and 6/ 7 boys) and 2 cases of penile lesions (one of them extensive perineal lesions in a HIV positive child - case 16). Some patients presented secreting lesions $(13,14,16)$, pruritus $(6,7,13$, $16)$, bleeding $(1,10,11,13,14,15,16)$, pain (14) or vaginal discharge $(11,12)$. Only one girl had internal thigh lesions (2). All children were examined under general anesthesia, in lithotomy position. None of the girls had a complete hymen laceration, but there were 4 cases of partial rupture and one case of thickening. In 1 boy, sexual abuse was evidenced by physical examination under anesthesia (endoanal adult pubic hair found, case 8), but 1 other had a perianal hematoma with no history of trauma (case 4). Anal sphincteric tonus was not considered, as patients were seen under anesthesia. Regarding physical evidence of sexual abuse, there was only one case of a sign with no possible explanation except sexual abuse (endoanal adult pubic hair, case 9), 3 hymeneal lesions suggestive of abuse (cases 2, 12 and 15) and one perianal hematoma without any known local trauma (case 4). Perineal examinations were normal in 9 patients.(Table 2). Time evolved between when the lesion was first seen by the child or parent and medical diagnosis varied between 15 days to more than a year (mean 3.5 months). Virus typing was possible only for patient 8 - viral subtypes $6 / 11$ and 16/18 - (Jesus et al., 1997).
All of the patients were tested for HIV and syphilis (serological tests), gonorrhea and trichomoniasis (only with gram and wet preparations of vaginal and rectal secretions). We could not test our patients for Clamidia and we had no access to gonococcal cultures. Patient 16 was a known symptomatic HIV positive (perinatally transmitted), but patient 2 was newly diagnosed as HIV (+), asymptomatic as yet. Two patients were diagnosed and treated for asymptomatic secondary syphilis. We could find no cases of gonorrhea or trichomoniasis in our patients.

We could detect 8 cases of sexual abuse and 5 cases of peripartum transmission (all preschoolers, cases 3, 6, 7, 16, 17, patient 6 had 2 infected brothers), in four patients the mechanism of transmission for the virus could not be determined. Case 4, a 9 y.o. boy with an unexplained perianal hematoma and behavioral abnormalities was lost to follow up. Cases 8 and 13, both 2 y.o. boys with no history of abuse or non-hygienic contact, mothers and fathers examined and excluded as carriers for the virus. Case 14, a 5 y.o. girl with no physical evidences of abuse and no history or circumstantial evidences of aggression. This patient's mother has vulvar condylomatous lesions, but the girl's warts appeared at 5 y.o. There is a story of non-hygienic contact and sharing towels with the mother (Table 1).

Familiar conditions for the sexually abused children were very adverse: $5 / 8$ had $<20$ y.o. mothers, $7 / 8$ of the mothers were divorced from the child's father, 3 of them had a new companion, one of them a third one. One of the mothers had a story of sexual promiscuity and drug addition. All children (except case 2 ) lived in very promiscuous houses ( 2 or more families living in the same house with insufficient room for everybody and/or a fluctuating population of visitors, including boy/girlfriends for the adults cohabiting frequently). Only $3 / 8$ parents were financially responsible for their children and just 3/8 fathers were constantly or frequently present. Also 3/8 fathers were completely absent. There was a history of familiar alcoholism or drug addiction in 3 cases and case 10 had a history of abuse against a cousin, witnessed - but not denounced - by the child's grandmother. All the children in the proper age had serious school problems. Between the nonabused-proven children, there were $2 / 6$ adolescent mothers (age of the mother in case 16 dead from HIV infection - is unknown), 3/ 6 divorced mothers, but only one new marriage. In $5 / 6$ families the father either cohabited or frequently visited the child and 5/ 6 parents were 
Table 2

Clinical signs and symptoms/physical examination.

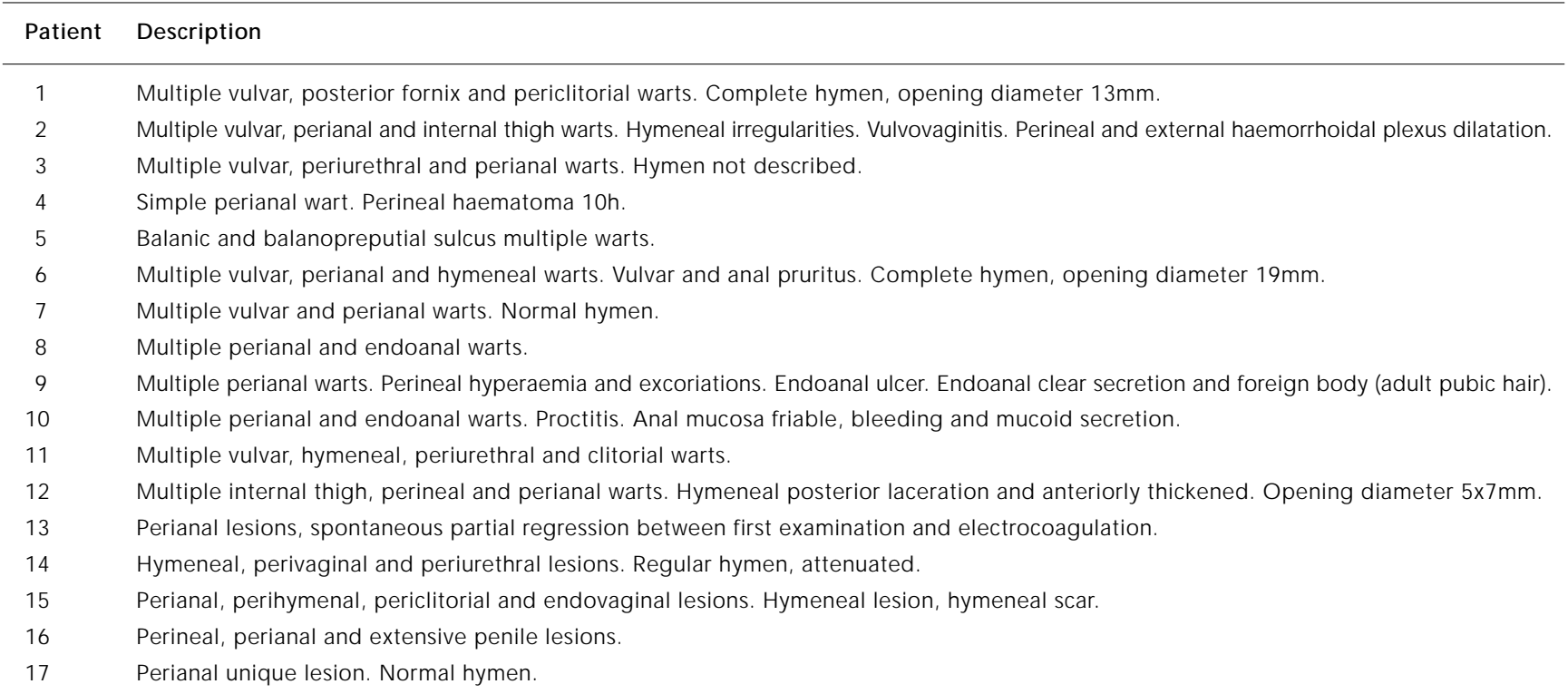

financially responsible for the child (case 16 orphan child).

Behavioral analysis showed that all of the mothers of victimized children cooperated with investigations and all of the families accepted well the investigative protocol after the initial explanations about the disease, except for one (case 2, mother previously denounced for child neglect and abuse). Generically people were shocked about the possibility of sexual abuse involving their children, but accepted it as possible, and wanted to exclude the possibility. One of the mothers was herself abused as a child, and was very anxious about her daughter (case 1). None of the children spontaneously related the aggression and none of them related it before a strong relationship between child and medical team was established as in-hospital patients. Of the abused children, 8/ 8 showed behavioral abnormalities: 8/ 8 introspection and retraction to contact, $1 / 8$ developmental regression, $4 / 8$ non-cooperative behavior towards medical team, $1 / 8$ sadness and maternal dependency. The mothers said these signs were "recent". We had no case of hypersexualized behavior. All of the $>5$ y.o. children were spontaneously better with these problems after surgery (this was not observed for the $<5$ y.o. patients).

In all cases we used electrocoagulation of the lesions as the only treatment, in 2 sessions in patients 8, 12 and 16 (to treat very extensive lesions). A very precocious recurrence was shown in patients 2 and 16 (HIV positive). Patient 16 is now having a trial with interferon. No other recurrence was detected in the follow up (minimum 6 months).

\section{Discussion}

Despite the persisting controversy about the mechanisms of contamination by HPV in childhood, there is a recently established bias to consider AGW in children as having no evidence for sexual abuse, especially among dermatologists and general pediatricians. This tendency explains the non-referral of those patients for evaluation. This roots in various references in pediatric literature dealing with the possibilities of non-aggressive inoculation of HPV in children (Allen, 1998; Cohen et al., 1990; Gutman et al., 1993; Heaton, 1995; Obalek et al., 1990; Sedlacek et al., 1989; Tseng, 1998) and to the general rejection of the idea of sexual manipulation of children (Craighill, 1998), which intensity is obviously related to the cultural background of the involved professionals. As a matter of fact, the specific references cited to non-aggressive non-perinatal inoculation on HPV in childhood are few (Bowen \& Aldous, 1999; Boyd, 1990; Paradise, 1990). They represent citations of a small collection of papers, and the majority of the tests are methodologi- 
cally limited in the investigation of sexual abuse (e.g. denial of abuse because there is no witness, spontaneous history by the victim or unquestionable evidence of violence) or show a bias regarding the age of the patients (e.g. papers with a large majority of preschoolers). We recognize that non- aggressive inoculation predominates in preschoolers, but it was not exclusive in our patients ( 3 cases of abuse in this group of patients) and, perhaps more important, all of our children $>5$ y.o were proved or very probable victims of abuse, except for 1 case, lost to follow up, in which abuse could not be proved, but is strongly suspected (Table 1). These facts, allied to the alarming numbers for childhood sexual abuse cited by various authors (Filkelhor, 1993) obliges us to always consider this possibility, especially in > 6 y.o children, as this is the major age group for abuse ( $>60 \%$ of cases) and in the case of perinatal transmission, this age group largely surpasses the time accepted for the latency of the virus.

In our cases we considered as sexual abuses only cases in which there was certainty (trustful history, witnessed abuse or medico-legal proof) or strong probabilities of abuse (pronounced behavioral or psychological modifications, unlinked to other facts and analyzed by our psychologists) (Bowen \& Aldous, 1999). With this criteria, we had evidence of $8 / 17$ cases of abuse $(2<3$ y.o. and $6>5$ y.o.). There was physical evidence of penetration in only one child (case 9) and there was no case of rape. This is in agreement with Paradise (1990), who states, indexes of up to $18 \%$ for physical evidence of abuse in girls and $17 \%$ in boys (physical examination under anesthesia). There may be a bias from our study, as we consider only children referred for non-urgency evaluation and with no complaints of trauma or spontaneous histories of aggression. In our patients, the strategies used by aggressors to obtain the child's cooperation usually involved friendly talking or playing, emotional menaces and small prizes.

It is very uncommon to obtain evidence of aggression in a first consultation with the child or parents. None of our patients spontaneously denounced aggressions in ambulatory consultations. All of our disclosures were obtained after a relatively long period of time, after hospital admission and initial treatment and after building a strong and trustworthy relationship with the child and his/her family and health team. This was very difficult - or impossible to obtain in preschoolers. We strongly agree with Paradise (Finkelhor, 1993) in the fact that admission in a hospital and examination under anesthesia helps a lot in the evaluation of these patients.

Perinatal transmission of HPV is definitely possible, but data is inconsistent about frequency and the mechanism of transmission (transvaginal and/ or other) (Ferenczy, 1995; Ingram et al., 1992; Moscicki, 1996; Pakarian et al., 1994), and there is definitive evidence that a Cesarean section is not protective. It is possible to detect a $20 \%$ presence of DNA from HPV in neonates, but viral DNA disappears in a great proportion of the babies by 6 weeks of age, suggesting that contamination not necessarily means infection or disease (Pakarian et al., 1994). As admitted maximum incubation period for AGW transmitted perinatally in children is 2 years (Davis \& Emans, 1989; Hammerschlag, 1998; Mosicki, 1996), that mechanism is a strong consideration only if the disease shows before 3 years old, but it is theoretically difficult to state that it is not possible for the infection to be present previously - in a latent state - and manifest at later ages as AGW. We think that abuse must be actively excluded even in younger children, as we could prove 1 case in our group of 9 preschooler patients and 1 case in a 4 y.o. child (Table 1).

Non-aggressive genital infection by HPV through auto or heteroinoculation is even more controversial. Some authors admit the possibility of perineal infection by the hands of children or adults caring for the child and by fomites. This is definitely possible, but its frequency and epidemiological importance are extremely questionable, at best. Cohen et al . (1990) and Obalek et al. (1990) suggest this possibility in a group of predominantly preschoolers and toddlers ( $77 \%$ of cases - Cohen et al., 1990), with an abnormally high incidence of maternal AGW (16\% - Cohen et al., 1990; >50\% - Obalek et al., 1990). In both clinical studies the authors did not detail the mechanisms used to exclude abuse, confirmed abuse only if there is a spontaneously obtained history or witness of abuse or included a majority of cases in which evidence for abuse was "inconclusive". Despite their belief in predominant nonaggressive transmission in preschoolers both authors agree that it is essential to exclude abuse even in this age group. Ingram et al. (1992), in a 1,538 childhood STD cases study documents $1,8 \%$ of $A G W$, and demonstrates non-aggressive transmission in $100 \%$ of $<1$ y.o., $71 \%$ of $1-2$ y.o., $50 \%$ of $4-7$ y.o. and zero in $>6$ y.o. We think that non-abusive, non-perinatal transmission of HPV in children, although possible, is conjectural, and is an exclusion diag- 
nosis, very uncommon - if at all present - in > 6 y.o. children.

Behavioral abnormalities were constant among our abused patients, and confirm other authors beliefs (Swanston et al., 1997). We must admit that social and familiar adverse conditions of our group of patients might explain some of the problems verified, but behavioral problems were present in only a minority of other patients evaluated for non-aggressive linked diseases in our hospital, from age matched and social background matched groups. It was interesting to verify a "normalization" of behavioral pattern in children after successful treatment of the warts. We could find no reference to this in literature, and we do not know its reasons. Perhaps we could attribute this to the background given to the child by our team, but our psychiatrist theorizes that the absence of macroscopic lesions as a constant evidence of the abuse has a role in behavioral modifications after treatment. For now we are not able to evaluate long term consequences of the aggression or its treatment in our patients, because of the relatively small follow up period, along with low self-esteem, depression, high incidence of suicide, criminality and adolescent pregnancy are known sequels of sexual aggression in childhood (Swanston et al., 1997).

Investigating or not studying other STD in those patients is controversial. By our protocol, we investigated syphilis and AIDS (serologic testing) in all patients, by a double dosage (ambulatory evaluation and during hospital admission). We also collected a vaginal smear for gonococcus research. Unfortunately our resources do not allow us to provide cultures for Neisseria Gonorrhoeaeand for Chlamydia. Statistical risk for gonorrhea in asymptomatic victims of sexual abuse in United States is 3\% (American Academy of Pediatrics Committee in Childhood Abuse and Neglect, 1991; Hammerschlag, 1998) and the American Association of Pediatrics (AAP) does not recommend systematic testing for all victims, limiting investigations to symptomatic cases, known epidemiological risks from the perpetrator and declared or evidenced penetration (American Academy of Pediatrics Committee in Childhood Abuse and Neglect, 1991; Hammerschlag, 1998). Even so, we have to consider that the risk of transmission of a STD in a sexual abuse case is related to the epidemiologic characteristics of the specific population group being studied, so the criteria of the AAP may not apply to our patients. Chlamydial infection in abuse victims is uncommon (Pandhi et al.,
1995) and usually asymptomatic. There are serious problems to evaluate a positive culture in $<3$ y.o., as there can be perinatal transmission, but a positive culture is considered evidence of abuse in older children (American Academy of Pediatrics Committee in Childhood Abuse and Neglect, 1991; Hammerschlag, 1998; Schwarcks \& Whittington, 1990). We had two syphilis and one AIDS case disclosed in our patients. The HIV positive child was a preschooler, victim of abuse, with a previous blood transfusion.

The prevalence of syphilis is high in poor non-educated populations ( $1 / 4$ of adults in India - Pandhi et al., 1995) and this encouraged us to use systematic testing in our patients. We generally do not worry to re-test after some time, as our patients are generally evaluated a long time after the AGW transmitted by sexual aggression appeared (mean 3.5 months). Gellert et al. (1993) showed $1.7 \%$ of HIV seropositivity in the victims of abuse with no other factors for infection. More recent articles recognize sexually transmitted HIV as a possibility in children (Lindegren et al., 1998). Although we could find a new case of $\mathrm{HIV}(+)$ by our systematic testing process, (patient 2) we cannot state that it was a case of sexually transmitted virus, as the child had a previous blood transfusion.

We adopted electrocoagulation of lesions as our preferred method for treatment, because of its cost, facilities of treating during a unique session under anesthesia, no sequel and a very low recurrence rate was confirmed by other authors (Hatch, 1995; Heaton, 1995; Moscicki, 1996). Treatment under anesthesia additionally favours a technically perfect physical examination without genital manipulation and discomfort in already abused children (Paradise, 1990). Until now there was only one case of recurrence (AIDS porter, case 16) and 1 child for whom it was necessary to have 2 electrocoagulation sessions for completion of the treatment. Mothers previously exposed to topic forms of treatment stated a preference for 1-session of electrocoagulation of lesions to other modalities, in spite of the necessity of general anesthesia or heavy sedation.

We are worried with the possible long-term consequences of HPV genital infection in childhood, as there are clearly pre-neoplastic viral subtypes and their frequency is unknown in children, even if we can presume an statistical frequency similar to adults, based on the predominant mechanisms of transmission. We plan to subtype the viruses in our patients and to study their differential incidence in the near future to study this hypothesis. 
Today there is a lot of controversy between an aggressive approach of possible sexual abuse, which can lead to unnecessary familiar stress and social stigmatization of the index patient (Bowen \& Aldous, 1999), and a "permissive" medical attitude towards cases of abuse that are not evident, which protects them from an eventually stressful and fruitless investigation. The absence of any treatment exposes the possibility of an abused child to continued aggression from the perpetrator and its sequel. We think that the answer to this dilemma is a professional, compassionate, systematic evaluation of these children. This evaluation needs to be unprejudiced and multidisciplinary, along with a necessary open discussion developed from a strong and positive patient-doctor relationship.

\section{Conclusions}

AGW in children is a controversial issue in medical literature. Viral transmission can be perinatal (up to 3 y.o.), from sexual abuse (especially $>6$ y.o.) or by auto/ heteroinoculation (controversial). In our service we treated children infected with HPV with a multidisciplinary approach. All are tested for syphilis and HIV. Tests for gonorrhea are done as necessary. All of the patients are examined under anesthesia and submitted to electrocoagulation of the warts as our preferential treatment, after a period of psychological analysis and assistance. We found it necessary to carefully analyze those patients for sexual abuse, as the incidence is high in porters of AGW, especially with infants and adolescents.

\section{References}

ALLEN, S., 1998. The natural history of condyloma in children. Journal of the American Academy of Dermatology, 39:951-955.

AMERICAN ACADEMY OF PEDIATRICS COM MITTEE IN CHILDHOOD ABUSE AND NEGLECT, 1991. Guidelines for the evaluation of sexual abuse in children. Pediatrics, 87:254-260.

BOWEN, K. \& ALDOUS, M. B., 1999. Medical evaluation of sexual abuse in children without disclosed or witnessed abuse. Archives of Pediatrics and Adolescent Medicine, 153:1160-1164.

BOYD, A. S., 1993. Condylomata acuminata in pediatric population. American Journal of Diseases of Children, 144:817-824

COHEN, B. A.; HORNIG, P. \& ANDROPHY, E., 1990. Anogenital warts in children: Clinical and virologic evaluation for sexual abuse. Archives of Dermatology, 126:1275-1280.

CRAIGHILL, M. C., 1998. Pediatric and adolescent Gynecology for the primary care pediatritian. $\mathrm{Pe}$ diatric Clinics of North America, 45:1659-1688.

DAVIS, A. J. \& EMANS, S. J., 1989. Human papillomavirus infection in the pediatric and adolescent patient. Journal of Pediatrics, 115:1-9. 
FERENCZY, A., 1995. Epidemiology and clinical pathophysiology of condylomata acuminata. American Journal of Obstetrics and Gynecology, 172:13311339.

FINKELHOR, D., 1993. Epidemiological factors in the clinical evaluation of childhood sexual abuse. Child Abuse \& Neglect, 17:67.

GELLERT, G. A.; DURFEE, M. J.; BERKOWITZ, C. D.; HIGGINS, K. V. \& TUBIOLO, V. C., 1993. Situational and sociodemographic characteristics of children infected with HIV from pediatric sexual abuse. Pediatrics, 72:16-21.

GUTMAN, L. T.; HERMAN-GIDDENS, P. A. \& PHELPS, W. C., 1993. Transmission of human genital papillomavirus disease: Comparison of data between adults and children. Pediatrics, 91:31-38.

HAM MERSCHLAG, M. R., 1998. Sexually transmitted diseases in sexually abused children: Medical and legal implications. Sexually Transmitted Infections, 74:167-174.

HATCH, K. D., 1995. Clinical appearance and treatment strategies for HPV: A gynaecologic perspective. American Journal of Obstetrics and Gynecology, 172:1340-1344.

HEATON, C. L., 1995. Clinical manifestations and modern management of condylomata acuminata: A dermatologic perspective. American Journal of Obstetrics and Gynecology, 172:1344-1350.

INGRAM, D. L.; EVERETT, V. D. \& LYNA, P. R., 1992. Epidemiology of adult sexually transmitted disease agents in children being evaluated for sexual abuse. Pediatric Infectious Disease Journal, 11: 945-950.

JESUS, L. E.; FRUGULHETTI, I. P. P. \& CHAGAS, P. B., 1997. Infecção perianal por HPV na infância. Jornal Brasileiro de DST, 9:40-41.

LINDEGREN, M. L.; HANSON, C.; HAMMETT, T. A.; BEIL, J.; FLEMING, P. L. \&WARD, J. W., 1998. Sexual abuse in children: Intersection with the HIV epidemic. Pediatrics, 102:E46.
MOSCICKI, A., 1996. Genital HPV infections in children and adolescents. Obstetric and Gynecology Clinics of North America, 23:675-697.

OBALEK, S.; JABLONSKA, S.; FAVRE, M.; WALCZAK, L. \& ORTH, G., 1990. Condylomata acuminata in children: Frequent association with papillomaviruses responsible for cutaneous warts. Journal of the American Academy of Dermatology, 23:205-213.

PAKARIAN, F.; KAYE, J.; CASON, J.; KELLY, B.; JEWERS, R.; DERIAS, N. W.; RAJU, K. S. \& BEST, J. M., 1994. Cancer associated papillomaviruses: Perinatal transmission and persistence. British Journal of Obstetrics and Gynaecology, 101:514-517.

PANDHI, R. K.; KHANNA, N. \& SEKHRI, R., 1995. Sexually transmitted disease in children. Indian $\mathrm{Pe}$ diatrics, 32:27-30.

PARADISE, J. E., 1990. The medical evaluation of the abused child. Pediatric Clinics of North America, 37:839-862, 1990.

SCHWARCKS, S. K. \& WHITTINGTON, W. L., 1990. Sexual assault and sexually transmitted diseases: Detection and management in adults and children. Reviews of Infectious Disease, 12:S682-689.

SEDLACEK, T. V.; LINDHEIM, S.; EDER, C.; HASTY, L.; WOODLAND, M.; LUDOMIRSKY, A. \& RANDO, R. F., 1989. Mechanism of human papillomavirus transmission at birth. American Journal of Obstetrics and Gynecology, 161:55-59.

SWANSTON, H. Y.; TEBBUT, J. S.; O'TOOLE, B. I. \& OATES, R. K., 1997. Sexually abused children 5 years after presentation: A case control study. Pediatrics, 100:600-608.

TSENG, A., 1998. Perinatal transmission of HPV in infants: Relationship between infection rates and mode of delivery. Obstetric and Gynecology, 91: 92-96. 